
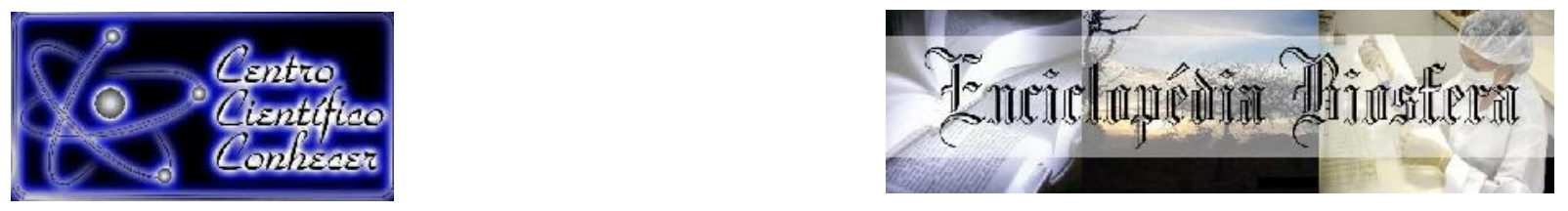

\title{
DIREITO E DIRETRIZES DE ACESSO A ÁGUA: CONTEXTO GERAL E ABORDAGEM PARA A CIDADE DE RIO BRANCO, ACRE, BRASIL
}

Carolina de Lima Accorsi Montefusco ${ }^{1}$; Daniela Silva Tamwing ${ }^{1}$; Wilians Montefusco da $\mathrm{Cruz}^{2}$; José Genivaldo do Vale Moreira ${ }^{3}$; Rodrigo Otávio Peréa Serrano ${ }^{3}$

- Engenheira Civil; Mestranda em Ciência, Inovação e Tecnologia para a Amazônia pela Universidade Federal do Acre, Rio Branco, Acre, Brasil.

(carolaccorsi@hotmail.com)

- Engenheiro Civil; Mestre em Processos Construtivos e Saneamento Urbano pela Universidade Federal do Pará.

- Professor do programa de pós-graduação em Ciência, Inovação e Tecnologia para a Amazônia da UFAC, Rio Branco, Acre, Brasil.

Recebido em: 15/08/2021 - Aprovado em: 15/09/2021 - Publicado em: 30/09/2021 DOI: 10.18677/EnciBio_2021C15

trabalho licenciado sob licença Creative Commons Attribution-NonCommercial-NoDerivatives 4.0 International License.

\begin{abstract}
RESUMO
A água é elemento essencial para a manutenção da vida e a universalização de sua oferta é um direito fundamental. O Brasil, apesar de ser o país com maior volume em água doce disponível, ainda há distribuição desproporcional. No sentido de garantir o

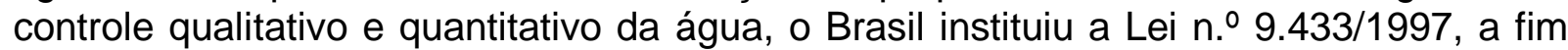
de regulamentar a Política Nacional de Recursos Hídricos. O instrumento contempla, entre outros, elementos de outorga, vazões de referência e medidas de proteção dos corpos hídricos. Atualmente, na cidade de Rio Branco, não há uma estimativa formal da vazão de referência utilizada, porém, os registros apontam para volumes cada vez menores no período árido que, juntamente com a captação sem um controle rígido, pode-se comprometer o manancial. Verificou-se que o sistema de abastecimento público de água na capital do estado do Acre deu início em 1957, e desde então passou por várias mudanças institucionais na prestação do serviço, apresentando descontinuidade das políticas públicas. Consequentemente, o panorama atual de Rio Branco é de apenas $52,66 \%$ da população total do município sendo atendida com rede pública de abastecimento de água.
\end{abstract}

PALAVRAS-CHAVE: Abastecimento de água, instrumentos de controle, segurança hídrica.

\section{WATER ACCESS LAW AND GUIDELINES: GENERAL CONTEXT AND APPROACH FOR THE CITY OF RIO BRANCO, ACRE, BRAZIL.}

\begin{abstract}
Water is an essential element for the maintenance of life and the universalization of its supply is a fundamental right. Brazil, despite being the country with the largest volume of available fresh water, still has a disproportionate distribution. In order to guarantee the qualitative and quantitative control of water, Brazil instituted Law No. 9,433/1997, in order to regulate the National Water Resources Policy. The instrument includes, among ENCICLOPÉDIA BIOSFERA, Centro Científico Conhecer - Jandaia-GO, v.18 n.37; p. 171 2021
\end{abstract}


others, grant elements, reference flows and measures to protect water bodies. Currently, in the city of Rio Branco, there is no formal estimate of the reference flow used, however, the records point to increasingly smaller volumes in the arid period which, together with abstraction without strict control, can compromise the source. It was found that the public water supply system in the capital of the state of Acre started in 1957, and since then it has undergone several institutional changes in the provision of the service, presenting discontinuity of public policies. Consequently, the current panorama of Rio Branco is only $52.66 \%$ of the total population of the municipality being served by the public water supply network.

KEYWORDS: water supply, water security, control instruments.

\section{INTRODUÇÃO}

A água é, de modo praticamente axiomático, um recurso fundamental à vida humana, quer na dimensão biológica, quer na dimensão social. Utilizada em atividades diversas como agricultura, pecuária, indústria e serviços gerais, sua abundância ou escassez podem ser fatores determinantes dos hábitos de consumo de uma comunidade (DIAS, 2011). Ela pode ainda influenciar no modo de vida, ajudando a construir laços sociais nas comunidades e favorecer o desenvolvimento (SELBORNE, 2002).

A disponibilidade de água potável promove o desenvolvimento, é um indicador do progresso dos povos e se constitui em um direito humano fundamental, sendo, inclusive, elemento basal ao exercício de outros direitos (PNUD, 2006). Machado (2002) acentua que a existência do ser humano - por si só - já lhe garante o direito à água e ao ar. Tamanha é sua importância, que os países que sofrem com sistemas de saneamento precários, ou mesmo inexistentes, são aqueles que revelam altas taxas de mortalidade, associadas à deficiência na qualidade do serviço de água e esgotamento sanitário ofertado (CASTRO, 2013).

O provimento adequado de água, em quantidade e qualidade, é essencial para o desenvolvimento socioeconômico, com reflexos diretos sobre as condições de saúde e de bem-estar da população. Condições adequadas de abastecimento resultam em melhoria das condições de vida e em benefícios como controle e prevenção de doenças, prática de hábitos higiênicos, conforto e bem-estar, aumento da expectativa de vida e da produtividade econômica (RAZZOLINI; GÜNTHER, 2008).

O crescimento populacional desordenado tem colaborado de forma significativa para a escassez de água, e inviabilizando oferta justa desse recurso, sobretudo aos menos favorecidos (EICHENBERGER et al., 2020). Segundo a Organização das Nações Unidas (ONU), através do Relatório Mundial das Nações Unidas sobre Desenvolvimento dos Recursos Hídricos (2019), mais de dois bilhões de pessoas vivenciam alto estresse hídrico, e cerca de quatro bilhões experimentam escassez severa de água durante pelo menos um mês do ano. Esses números tendem a crescer à medida que a demanda por água aumenta e a oferta de água tratada diminui.

O contexto presente potencializa a incorporação de instrumentos mais racionais ao processo de gestão dos recursos hídricos, que tem por objetivo alinhar as demandas econômicas, sociais e ambientais em níveis sustentáveis a fim de mediar os conflitos de usos atuais e assegurar a oferta futura da água (SILVA; MONTEIRO, 2004). Os conflitos relacionados ao acesso regular à água potável e segura têm causado preocupação, principalmente nos países em desenvolvimento, que sofrem com a rápida ENCICLOPÉDIA BIOSFERA, Centro Científico Conhecer - Jandaia-GO, v.18 n.37; p. 172 
expansão urbana, adensamento populacional e com a ocupação de áreas periurbanas e rurais. São cada vez mais contundentes as evidências relatadas quanto às dificuldades no suprimento de água às necessidades básicas diárias (RAZZOLINI; GÜNTHER, 2008).

O acesso regular à água potável e segura, embora seja um direito humano básico, não tem sido estendido a toda a população, especialmente àquela encontrada em áreas não contempladas pelas políticas públicas de saneamento e saúde (RAZZOLINI; GÜNTHER, 2008). O acesso à água e ao saneamento integra o conteúdo mínimo do direito à dignidade da pessoa humana, devendo-se respeitar alguns requisitos, tais como: qualidade a ser oferecida obedecendo-se os padrões de potabilidade, quantidade suficiente para a sobrevivência humana, e garantindo o acesso humano facilitado e gratuito (MAIA, 2017).

Trata-se do reconhecimento de que o direito ao acesso a água é um direito humano fundamental e que deve ser distribuído de modo igualitário a todos os cidadãos, sob pena de se ferir a dignidade humana, haja vista que não existe vida sem água e não há como se viver dignamente se seu acesso é falho ou até mesmo inexistente (CASTRO, 2013). De forma preocupante, a água potável existente no planeta tende a se tornar ainda mais escassa, por diversos fatores, entre os quais o crescimento demográfico, a urbanização, a expansão da agricultura e o grau de industrialização. Os diversos interesses ao uso da água intensificam a crise de abastecimento em dimensões mundiais, conforme alertam Reymão e Saber (2009).

Para Pontes e Schramm (2004), o problema do acesso à água deve ser visto como questão de saúde pública, podendo ser abordado sob a ótica da bioética de proteção, uma ética da responsabilidade social, em que o Estado deve se basear para assumir suas obrigações sanitárias para com as populações humanas (SCHRAMM; KOTTOW, 2001). Para esses autores, as medidas que legitimam o papel do Estado como protetor da saúde pública (no que se refere à água potável) devem ser aquelas que possibilitem a todo cidadão dispor de água em quantidade suficiente e qualidade adequada para atender às suas necessidades básicas. Cabe ao Estado identificar as situações em que há desigualdades de acesso e desenvolver políticas públicas para resolver esses problemas.

De fato, sem o acesso a uma quantidade mínima de água potável, os outros direitos a ela intrínsecos, tais como os direitos à vida e a um nível adequado para a saúde e bem-estar, tornam-se inatingíveis. Entretanto, a disponibilidade de água atualmente atravessa uma grande crise de escassez (MAIA, 2017). Segundo os estudos da World Health Organization e Unicef (2014), 769 milhões de indivíduos são afetados por escassez ou falta de acesso à água no globo.

Garantir água em quantidade e qualidade adequadas para todos os seres humanos e atividades econômicas em um mundo cada vez mais habitado, com tendência de acréscimo nos níveis de aridez, é um dos grandes desafios da humanidade no século 21. As crises hídricas em diferentes regiões do planeta são uma boa amostra do que nos espera no futuro e reforçam urgência na construção de uma nova forma de viver e se relacionar com a água (MAIA, 2017). 


\section{Acesso à água: Abordagem internacional}

O acesso à água potável e ao saneamento básico é um direito humano essencial, fundamental e universal, indispensável à vida com dignidade e reconhecido pela Organização das Nações Unidas (ONU) como condição para o gozo pleno da vida e dos demais direitos humanos por meio da Resolução 64/A/RES/64/292, de 28.07.2010 (ONU, 2010). Sendo assim, o reconhecimento como direito fundamental veio de forma tardia, pois apenas no ano de 2010 foi que se mencionou expressamente em um texto internacional.

O estudo conduzido por Maia (2017) expõe que esse quadro normativo foi se aperfeiçoando, compreendendo-se a importância da água como garantia dos demais direitos humanos e sua relação com a dignidade humana. A propósito, no Quadro 1 são apresentados os principais marcos internacionais acerca do direito humano à água e ao saneamento divulgado pela Organização das Nações Unidas.

QUADRO 1: Principais marcos internacionais acerca do direito a água.

\begin{tabular}{|c|c|c|}
\hline DATA & INSTRUMENTO & DESCRIÇÃO \\
\hline $\begin{array}{l}\text { Março de } \\
1977\end{array}$ & $\begin{array}{l}\text { Plano de Ação da Conferência } \\
\text { da ONU sobre a água, Mar da } \\
\text { Prata }\end{array}$ & $\begin{array}{l}\text { Primeira Conferência específica sobre a água. } \\
\text { Reconhece, de forma inédita, o direito de todos } \\
\text { os povos, quais forem o seu estágio de } \\
\text { desenvolvimento e as suas condições sociais e } \\
\text { econômicas, de acesso à água potável em } \\
\text { quantidade e qualidade igual às suas } \\
\text { necessidades básicas. }\end{array}$ \\
\hline $\begin{array}{l}\text { Dezembro } \\
\text { de } 1979\end{array}$ & $\begin{array}{l}\text { Convenção sobre a } \\
\text { Eliminação de Todas as } \\
\text { Formas de Discriminação } \\
\text { contra as Mulheres } \\
\text { (Promulgada no Brasil pelo } \\
\text { Decreto } \mathrm{n}^{\circ} 4.377 \text {, de } 13 \text { de } \\
\text { setembro de 2002) }\end{array}$ & $\begin{array}{l}\text { Define, entre os direitos a serem assegurados às } \\
\text { mulheres pelos Estados signatários, o acesso à } \\
\text { água potável e ao saneamento. }\end{array}$ \\
\hline $\begin{array}{l}\text { Novembro } \\
\text { de } 1989\end{array}$ & $\begin{array}{l}\text { Convenção sobre os Direitos } \\
\text { da Criança (Promulgada no } \\
\text { Brasil pelo Decreto no } 99.710 \text {, } \\
\text { de } 21 \text { de novembro de 1990). }\end{array}$ & $\begin{array}{l}\text { A água e o saneamento básico devem ser } \\
\text { garantidos pelos Estados a todas as crianças, a } \\
\text { fim de combater doenças, desnutrição e } \\
\text { mortalidade infantil }\end{array}$ \\
\hline $\begin{array}{l}\text { Janeiro de } \\
1992\end{array}$ & $\begin{array}{c}\text { Conferência de Dublin sobre a } \\
\text { Água e o Desenvolvimento } \\
\text { Sustentável. }\end{array}$ & $\begin{array}{l}\text { O Quarto Princípio da Conferência reconhece a } \\
\text { importância de garantir água e o saneamento } \\
\text { básico a todos os seres humanos }\end{array}$ \\
\hline $\begin{array}{l}\text { Junho de } \\
1992\end{array}$ & $\begin{array}{l}\text { Conferência das Nações } \\
\text { Unidas sobre o Ambiente e o } \\
\text { Desenvolvimento. }\end{array}$ & $\begin{array}{l}\text { A Agenda } 21 \text { da Conferência consolida o direito } \\
\text { de todos os povos à água potável. }\end{array}$ \\
\hline $\begin{array}{l}\text { Setembro } \\
\text { de } 1994\end{array}$ & $\begin{array}{c}\text { Programa de Ação da } \\
\text { Conferência Internacional da } \\
\text { ONU sobre População e } \\
\text { Desenvolvimento. }\end{array}$ & $\begin{array}{l}\text { Inclui no direito a um nível de vida adequado o } \\
\text { acesso à água potável. }\end{array}$ \\
\hline $\begin{array}{l}\text { Dezembro } \\
\text { de } 1999\end{array}$ & $\begin{array}{c}\text { Resolução da Assembleia } \\
\text { Geral da ONU A/Res/54/175: } \\
\text { "O Direito ao } \\
\text { Desenvolvimento". }\end{array}$ & $\begin{array}{l}\text { Resolve que a garantia à água limpa é } \\
\text { fundamental para concretizar o direito ao } \\
\text { desenvolvimento e um imperativo moral para os } \\
\text { países a e comunidade internacional. }\end{array}$ \\
\hline
\end{tabular}




\begin{tabular}{|c|c|c|}
\hline $\begin{array}{l}\text { Setembro } \\
\text { de } 2002\end{array}$ & $\begin{array}{c}\text { Declaração Política da } \\
\text { Conferência Mundial sobre } \\
\text { Desenvolvimento Sustentável. }\end{array}$ & $\begin{array}{l}\text { Compreende o acesso à água limpa como forma } \\
\text { de garantir a dignidade da pessoa humana. }\end{array}$ \\
\hline $\begin{array}{l}\text { Novembro } \\
\text { de } 2002\end{array}$ & $\begin{array}{l}\text { Comentário Geral no15 sobre } \\
\text { o Pacto Internacional de } 1966 \\
\text { sobre os Direitos Econômicos, } \\
\text { Sociais e Culturais } \\
\text { (Incorporado ao Direito } \\
\text { Brasileiro pelo Decreto no } 591 \text {, } \\
\text { de } 06 \text { de julho de 1992). }\end{array}$ & $\begin{array}{l}\text { O Comentário Geral interpreta os artigos } 11 \text { e } 12 \\
\text { do Pacto Internacional para confirmar o direito à á } \\
\text { água. Além disso, explicita que a água é } \\
\text { fundamental para a dignidade humana e } \\
\text { realização dos outros direitos humanos. }\end{array}$ \\
\hline 2003 & $\begin{array}{l}\text { Comitê de Alto Nível sobre } \\
\text { Programas }\end{array}$ & $\begin{array}{l}\text { Criação da ONU Água - um mecanismo } \\
\text { interagencial para coordenar as ações do } \\
\text { Sistema das Nações Unidas para alcançar as } \\
\text { metas relacionadas à água }\end{array}$ \\
\hline $\begin{array}{l}\text { Julho de } \\
2005\end{array}$ & $\begin{array}{l}\text { Projeto de Diretrizes para a } \\
\text { Concretização do Direito a } \\
\text { Água Potável e Saneamento } \\
\text { do Conselho Econômico e } \\
\text { Social da } \\
\text { ONU.E/CN.4/Sub.2/2005/25 }\end{array}$ & $\begin{array}{l}\text { As diretrizes orientam os países a } \\
\text { implementarem o acesso à água e ao } \\
\text { saneamento básico por toda população. }\end{array}$ \\
\hline $\begin{array}{l}\text { Novembro } \\
\text { de } 2006\end{array}$ & $\begin{array}{l}\text { Decisão 2/104 do Conselho } \\
\text { dos Direitos Humanos. }\end{array}$ & $\begin{array}{l}\text { Buscou a relação, ao abrigo dos instrumentos } \\
\text { internacionais, entre os direitos humanos e o } \\
\text { acesso à água potável. }\end{array}$ \\
\hline $\begin{array}{l}\text { Dezembro } \\
\text { de } 2006\end{array}$ & $\begin{array}{l}\text { Convenção sobre os Direitos } \\
\text { das Pessoas com Deficiência } \\
\text { (Promulgada no Brasil pelo } \\
\text { Decreto no } 6.949 \text {, de } 25 \text { de } \\
\text { agosto de 2009). }\end{array}$ & $\begin{array}{l}\text { O direito das pessoas com deficiência à vida } \\
\text { adequada inclui o acesso à água limpa. }\end{array}$ \\
\hline $\begin{array}{l}\text { Agosto de } \\
2007\end{array}$ & $\begin{array}{l}\text { Relatório do Alto Comissário } \\
\text { das Nações Unidas para os } \\
\text { Direitos Humanos sobre a } \\
\text { abrangência e o teor das } \\
\text { obrigações relevantes em } \\
\text { termos de direitos humanos } \\
\text { relacionadas com o acesso } \\
\text { equitável a água potável } \\
\text { segura e saneamento, ao } \\
\text { abrigo dos instrumentos } \\
\text { internacionais de direitos } \\
\text { humanos. }\end{array}$ & $\begin{array}{l}\text { Na sequência da Decisão } 2 / 104 \text { do Conselho } \\
\text { dos Direitos Humanos, o relatório do Alto } \\
\text { Comissário para os Direitos Humanos refere que } \\
\text { "É chegada a altura de considerar o acesso a } \\
\text { água potável segura e ao saneamento como um } \\
\text { direito humano, definido como o direito a acesso } \\
\text { igual e não-discriminatório a uma quantidade } \\
\text { suficiente de água potável por pessoa e para os } \\
\text { usos domésticos... de forma a assegurar a vida } \\
\text { e a saúde". }\end{array}$ \\
\hline $\begin{array}{l}\text { Março de } \\
2008\end{array}$ & $\begin{array}{l}\text { Resolução do Conselho dos } \\
\text { Direitos Humanos } \\
\text { A/HRC/RES/7/22. } \\
\end{array}$ & $\begin{array}{l}\text { Decide-se nomear relator especial para a } \\
\text { questão dos direitos humanos relacionados à } \\
\text { água. }\end{array}$ \\
\hline $\begin{array}{l}\text { Outubro de } \\
\quad 2009\end{array}$ & $\begin{array}{l}\text { Resolução do Conselho dos } \\
\text { Direitos Humanos } \\
\text { A/HRC/RES/12/8. } \\
\end{array}$ & $\begin{array}{l}\text { Insta os Estados a acabarem com as } \\
\text { desigualdades no acesso à água e ao } \\
\text { saneamento. }\end{array}$ \\
\hline $\begin{array}{l}\text { Julho de } \\
2010\end{array}$ & $\begin{array}{l}\text { Resolução da Assembleia } \\
\text { Geral da ONU A/RES/64/292. }\end{array}$ & $\begin{array}{l}\text { A Assembleia reconheceu formalmente o direito } \\
\text { à água e ao saneamento como direitos } \\
\text { humanos. Convidou todos os Estados a } \\
\text { cooperarem para a garantia desses direitos a }\end{array}$ \\
\hline
\end{tabular}




\begin{tabular}{|c|c|c|}
\hline & & todos os povos. \\
\hline $\begin{array}{c}\text { Setembro } \\
\text { de } 2010\end{array}$ & $\begin{array}{l}\text { Resolução do Conselho dos } \\
\text { Direitos Humanos } \\
\text { A/HRC/RES/15/9. }\end{array}$ & $\begin{array}{l}\text { O Conselho confirmou que o direito à água e ao } \\
\text { saneamento é imperativo para os Estados. } \\
\text { Pediu aos Estados que atuem para } \\
\text { concretização de todos os direitos humanos. }\end{array}$ \\
\hline $\begin{array}{c}\text { Abril de } \\
2011\end{array}$ & $\begin{array}{l}\text { Resolução do Conselho dos } \\
\text { Direitos Humanos } \\
\text { A/HRC/RES/16/2. }\end{array}$ & $\begin{array}{l}\text { O Conselho encorajou a concretização integral } \\
\text { do direito humano à água e ao saneamento. }\end{array}$ \\
\hline $\begin{array}{l}\text { Outubro de } \\
2011\end{array}$ & $\begin{array}{l}\text { Resolução do Conselho dos } \\
\text { Direitos Humanos } \\
\text { A/HRC/RES/18/1. }\end{array}$ & $\begin{array}{l}\text { O Conselho reafirmou a responsabilidade dos } \\
\text { Estados de promoverem todos os direitos } \\
\text { humanos por meio de planos e programas } \\
\text { políticos, além de cooperação financeira e } \\
\text { técnica. }\end{array}$ \\
\hline $\begin{array}{c}\text { Outubro de } \\
2012\end{array}$ & $\begin{array}{l}\text { Resolução do Conselho dos } \\
\text { Direitos Humanos } \\
\text { A/HRC/RES/21/2. }\end{array}$ & $\begin{array}{l}\text { O Conselho expressou sua preocupação com o } \\
\text { impacto negativo da discriminação e } \\
\text { marginalização de certos grupos em seu acesso } \\
\text { à água potável. Exortou os Estados a darem } \\
\text { prioridade a esse direito e a assegurarem o } \\
\text { desenvolvimento sustentável }\end{array}$ \\
\hline $\begin{array}{l}\text { Outubro de } \\
2013\end{array}$ & $\begin{array}{l}\text { Resolução do Conselho dos } \\
\text { Direitos Humanos } \\
\text { A/HRC/RES/24/18. }\end{array}$ & $\begin{array}{l}\text { O Conselho incentivou a união dos Estados para } \\
\text { alcançarem as Metas do Milênio em matéria de } \\
\text { água e saneamento. Reafirmou a } \\
\text { responsabilidade dos Estados de garantirem } \\
\text { esses direitos e, para tanto, incentivou as } \\
\text { políticas sustentáveis. }\end{array}$ \\
\hline $\begin{array}{l}\text { Outubro de } \\
2014\end{array}$ & $\begin{array}{l}\text { Resolução do Conselho dos } \\
\text { Direitos Humanos } \\
\text { A/HRC/RES/27/7. }\end{array}$ & $\begin{array}{l}\text { O Conselho destacou a importância da } \\
\text { cooperação internacional para garantia dos } \\
\text { direitos à água e ao saneamento e dos recursos } \\
\text { a serem utilizados em caso de violação a esses } \\
\text { direitos. Os Estados devem promover a } \\
\text { efetividade progressiva dos direitos à água } \\
\text { potável e ao saneamento básico. }\end{array}$ \\
\hline
\end{tabular}

Fonte: Autores (2021).

Dessa forma, pode-se analisar que os documentos da ONU (2019) colocam como meta as condições igualitárias e não discriminatórias ao acesso à água; participação e inclusão das comunidades, povos e populações nos debates sobre os recursos, e a responsabilidade dos Estados, que deverão prover e garantir a disponibilidade, a qualidade, a acessibilidade física e econômica ao recurso. Os mesmos conceitos também compõem os direitos ao saneamento, incluindo a privacidade e a dignidade de acesso, agregados em resoluções posteriores.

O direito humano à água é uma questão complexa. Ao mesmo tempo em que os países concordam e reconhecem sua importância, muitos não possuem os meios tecnológicos e financeiros para garantir 0 acesso a demanda de sua população (MAZARO, 2021).

\section{Acesso à água: Abordagem nacional}

Segundo dados do Sistema Nacional de Informações sobre Saneamento (SNIS), divulgados em 2019, com referência à 2018, mais de $16 \%$ da população, ou quase 35 milhões de pessoas, não tinha acesso à água tratada no Brasil. O relatório aponta ainda que 
o problema é mais crítico na Região Norte, onde 42,9\% dos domicílios encontram-se nessa situação, seguida pelas Regiões Nordeste (25,8\%), Centro-Oeste $(11,0 \%)$, Sul $(9,8 \%)$ e Sudeste $(9,0 \%)$.

Mesmo em países com grande disponibilidade hídrica, como é o caso do Brasil, os problemas de escassez se fazem presentes, cujas origens passam por causas naturais, por excessiva demanda, além de desperdício (LUCENA et al., 2013). A preocupação com a degradação e a escassez dos recursos hídricos tem deixado de ser uma bandeira de luta apenas de ambientalistas, para assumir lugar de destaque na agenda de autoridades, comunidade científica e sociedade em geral (MORAES; JORDÃO, 2002; SELBORNE, 2002).

Reymão e Saber (2009) vêem sérios problemas na gestão dos recursos hídricos no Brasil, pois além das elevadas taxas de desperdício, há carência de investimentos no meio rural e de planejamento, prevalecendo a falta de infraestrutura, o que restringe os direitos de acesso à água para grande parte da população. A fragmentação de políticas públicas e a carência de instrumentos de regulamentação e regulação também estão entre os fatores relacionados ao déficit dos serviços de água e esgoto no País (NASCIMENTO; HELLER, 2005).

No que tange à disponibilidade de recursos hídricos, o Brasil ocupa posição de destaque, caracterizando-se como um país com abundância relativa desses recursos. Com cerca de $3 \%$ da população mundial, possui por volta de $12 \%$ da água potável superficial do planeta, distribuído de forma irregular, cuja vazão total de seus rios alcança $180 \mathrm{mil} \mathrm{m} 3 / \mathrm{s}$. A disponibilidade de água total bruta por brasileiro de aproximadamente $33.776 \mathrm{~m}^{3}$ de água/ano, que representa quase 20 vezes o limite considerado de estresse hídrico, que é de $1.700 \mathrm{~m}^{3} / \mathrm{ano}$, segundo a ONU (CONTI; SCHROEDER, 2013).

O Brasil é o País que possui o maior volume de água doce disponível, porém o recurso está distribuído de maneira desigual pelo território. Há mais água na região Norte, com cerca de $68 \%$ dos recursos hídricos e no Centro-Oeste (16\%) do País do que nas regiões Sudeste, Sul e Nordeste, com proporções de $6 \%, 7 \%$ e $3 \%$, respectivamente (SARRETA, 2013). As regiões com mais água doce disponível possuem a menor demanda por água. Já nas regiões com as maiores necessidades de recursos hídricos, há pouca água para atender aos diferentes usos.

O direito humano à água, assim como o direito humano à alimentação adequada, se realiza de forma progressiva e contínua. Os países signatários dos pactos de direitos internacionais, como o Brasil, têm a obrigação de respeitar, proteger e cumprir a realização desse direito, criando todas as condições para a sua realização, por meio da ampliação dos recursos humanos e financeiros e da implementação de um conjunto de políticas públicas que assegurem sua efetivação crescente e contínua (CONTI; SCHROEDER, 2013).

A Constituição Federal não traz expressamente no rol dos direitos fundamentais o acesso à água potável como direito básico a vida humana, porém claramente afirma sobre a inviolabilidade do direito à vida (CF, artigo 5o, caput). Castro (2013) concluiu que, por clara necessidade, verifica-se que o direito à vida só poderá ser exercido na sua plenitude se os indivíduos tiverem acesso à água de qualidade. Neste viés, é relevante o que concluiu Machado (2002), ao alertar que negar água ao ser humano é negar-lhe o direito à vida. No Quadro 2, apresenta-se um resumo das principais ações referentes ao estabelecimento do acesso a água no Brasil. 
QUADRO 2: Principais ações ao estabelecimento do acesso à água no Brasil.

\begin{tabular}{|c|c|c|}
\hline DATA & INSTRUMENTO & DESCRIÇÃO \\
\hline $\begin{array}{l}\text { Década de } \\
\qquad 70\end{array}$ & $\begin{array}{l}\text { PLANASA - Plano } \\
\text { Nacional de } \\
\text { Saneamento }\end{array}$ & $\begin{array}{l}\text { Instituição do Plano de Metas e Bases para a ação } \\
\text { do governo que definiu metas para o setor de } \\
\text { saneamento. }\end{array}$ \\
\hline 1995 & $\begin{array}{l}\text { Lei } 8.987 \text { - Lei de } \\
\text { Concessões e } \\
\text { Permissão do Serviço } \\
\text { Público }\end{array}$ & $\begin{array}{l}\text { Marco para a prestação do serviço público, } \\
\text { conforme previsão do artigo } 175 \text { da Constituição. }\end{array}$ \\
\hline 1999 & $\begin{array}{l}\text { 1a Conferência } \\
\text { Nacional de } \\
\text { Saneamento }\end{array}$ & $\begin{array}{l}\text { Apontou para a necessidade de universalização do } \\
\text { acesso ao saneamento e a necessidade da } \\
\text { qualidade no atendimento. }\end{array}$ \\
\hline 2003 & $\begin{array}{l}\text { Premissas da Política } \\
\text { Nacional de } \\
\text { Saneamento }\end{array}$ & $\begin{array}{l}\text { Em torno de } 3.457 \text { cidades, por intermédio de seus } \\
\text { representantes foram iniciados os primeiros } \\
\text { debates acerca das premissas da Política Nacional } \\
\text { de Saneamento. }\end{array}$ \\
\hline 2005 & Conferência & $\begin{array}{l}\text { Objetivou reforçar as estratégias do saneamento } \\
\text { aliada ao desenvolvimento urbano. }\end{array}$ \\
\hline 05 jan. 2007 & Lei 11.445 & $\begin{array}{l}\text { Estabelece as diretrizes nacionais para o } \\
\text { saneamento básico e institui a Política Federal de } \\
\text { Saneamento Básico. }\end{array}$ \\
\hline 15 jul. 2020 & Lei 14.026 & Sanciona o Marco Legal do Saneamento. \\
\hline
\end{tabular}

Fonte: Autores (2021).

Em 15 de julho de 2020, foi sancionada pelo Governo Federal a lei no 14.026 conhecida por novo marco legal do saneamento básico, se tornando o instrumento que visa assegurar maior garantia de implantação do serviço de saneamento básico no país. Seu objetivo é universalizar e qualificar a prestação de serviço nesse setor, através de ampliação de investimentos privados nessa área. A meta é aumentar o índice de acesso ao saneamento básico no Brasil, aumentando a cobertura de fornecimento de água potável para quase toda a população $(99 \%)$ e de $90 \%$ para coleta e tratamento de esgoto, em um horizonte de treze anos. Acredita-se que a nova lei contribuirá, adicionalmente, para a revitalização de bacias hidrográficas, a conservação do meio ambiente e a redução de perdas de água, além de proporcionar mais qualidade de vida e saúde à população.

\section{Disponibilidade hídrica e a oferta de água}

A preocupação com o aumento da demanda e a carência de recursos hídricos, no contexto da sustentabilidade ambiental discutida na Eco-92, gerou a necessidade de definir critérios e parâmetros de avaliação da disponibilidade hídrica de uma região ou país, de forma a hierarquizar as demandas e disponibilidade regionais e subsidiar as políticas públicas de gestão dos recursos hídricos e de desenvolvimento social (BRANCO, 2006).

Segundo Ribeiro et al. (2005), o conhecimento da disponibilidade hídrica é parte fundamental dos estudos hidrológicos. Dessa forma, existem diversas ferramentas que facilitam e auxiliam seu gerenciamento, como as vazões de permanência $Q_{90}, Q_{95}$ e a vazão ecológica $Q_{7,10}$, utilizadas para a avaliação do atendimento aos padrões ENCICLOPÉDIA BIOSFERA, Centro Científico Conhecer - Jandaia-GO, v.18 n.37; p. 178 2021 
ambientais do corpo receptor, para a alocação de cargas poluidoras e para a concessão de outorgas de captação e de lançamento (VON SPERLING, 2007).

Métodos estatísticos também são amplamente utilizados nesses estudos e, quando associados com análises de tendência, possibilitam a avaliação de longas séries de dados, sendo úteis para o acompanhamento e previsão da evolução de alguns fatores hidrológicos (TRINDADE et al., 2017). Portanto, a disponibilidade hídrica é estabelecida a partir de registros do passado, observadas em estações de monitoramento.

A Política Nacional de Recursos Hídricos (Lei no 9.433, de 8 de janeiro de 1997) institui que a gestão dos recursos hídricos deve sempre proporcionar o uso múltiplo das águas. No entanto, a distribuição não uniforme de água nas regiões hidrográficas brasileiras e a concentração da população em áreas urbanas geram demanda excessiva, que supera a disponibilidade. Essa necessidade acarreta problemas de escassez, tornando necessária a busca por mananciais superficiais, cada vez mais distantes, como também a exploração de mananciais subterrâneos, para suprir a demanda básica.

\section{Outorga de uso da água}

Segundo a Constituição Federal de 1988, a água é um bem de domínio público, seja ele da União ou dos Estados. No Brasil, com a instituição da Lei no 9.433 de 1997, conhecida como Lei das Águas, é estabelecida a Política Nacional de Recursos Hídricos $(\mathrm{PNRH})$, que propõe instrumentos para a gestão e regulação dos recursos hídricos no país. Entre tais instrumentos se destaca a outorga de direito de uso da água, que tem como objetivo garantir o controle quantitativo e qualitativo dos recursos hídricos, assim como o efetivo direito de acesso aos diferentes usuários deste recurso natural.

Por intermédio desse instrumento, é possível controlar os volumes captados, o período em que as captações ocorrem e qual a finalidade, contemplando os usos prioritários e as determinações dos planos de recursos hídricos e dos comitês de bacia hidrográfica (OLIVEIRA; FIOREZE, 2011).

De acordo com a Agência Nacional de Águas e Saneamento (ANA), a outorga de direito de uso de recursos hídricos é o instrumento da Política de Recursos Hídricos que tem os objetivos de assegurar:

- o controle quantitativo e qualitativo dos usos da água; e

- o efetivo exercício dos direitos de acesso à água.

A outorga é o ato administrativo mediante o qual o poder público outorgante (União, Estados ou Distrito Federal) faculta ao outorgado (requerente) o direito de uso de recursos hídricos, por prazo determinado, nos termos e nas condições expressas no respectivo ato (ANA, 2011). A concessão de direito ao uso dos recursos hídricos é um instrumento clássico de comando e controle, por meio do qual a administração autoriza uma pessoa física ou jurídica, pública ou privada, a usar água de um manancial para abastecimento humano ou animal ou para alguma atividade econômica (ANA, 2019).

Essa autorização do direito ao uso dos recursos hídricos deve ser solicitada por todos aqueles que usam, ou pretendem usar, os recursos hídricos, seja para captação de águas, superficiais ou subterrâneas, seja para lançamento de efluentes ou para qualquer ação que interfira no regime hídrico existente, além do uso de potenciais 
hidrelétricos. No caso das águas subterrâneas, a outorga deve ser emitida pelo poder público estadual ou do Distrito Federal (ANA, 2011).

Vale ressaltar que a ANA é a responsável por emitir outorgas para rios, reservatórios, lagos e lagoas sob o domínio da União, que são aqueles corpos de água que passam por dois ou mais estados ou, ainda, aqueles que passam pela fronteira entre o Brasil e outro país. Já as águas subterrâneas e os cursos de água que banham apenas um estado ou o Distrito Federal são outorgadas pelos poderes públicos estaduais ou distrital (ANA, 2011).

A definição da outorga e da respectiva vazão outorgável (quantidade de água a ser disponibilizada para os diversos usos), para além de critérios meramente hidrológicos, deve levar em conta as opções e as metas de desenvolvimento social e econômico que se pretende atingir, considerando os múltiplos usos, a capacidade de suporte do ambiente e a busca do desenvolvimento sustentável. A outorga é um dos instrumentos de gerenciamento de recursos hídricos que faz a articulação com a gestão ambiental (ANA, 2011).

A outorga é importante para que a administração conheça o perfil de uso da água na bacia hidrográfica e acompanhe sua evolução. Além disso, a outorga é uma garantia dada pelo Estado ao usuário de água, assegurando que a água será alocada a ele e não a terceiros. Isto visa a conferir segurança jurídica aos investimentos necessários aos empreendimentos que usam água (ANA, 2019).

Para que a implantação do instrumento da outorga possa ser realizada de maneira mais efetiva, é necessário o conhecimento do comportamento hidrológico das bacias hidrográficas, especificamente na determinação das vazões de referência ao processo decisório (FIOREZE; OLIVEIRA, 2010).

\section{Vazões de referência}

Para Silva et al. (2006), a vazão de referência é o estabelecimento de um valor de vazão que passa a representar o limite superior de utilização da água em um curso d'água e é, também, um dos elementos da implementação de um sistema de outorga. Já Silva e Monteiro (2004) destacam que as vazões de referência disponíveis durante maior parte do ano conferem maior segurança à alocação de água, mas podem inibir os usos, enquanto a adoção de vazões de referência menos restritivas pode levar ao desabastecimento de usos outorgados em alguns períodos, além de comprometer os ecossistemas envolvidos no manancial.

Assim a definição da vazão de referência a ser aplicada depende da garantia de atendimento que se considera para os usos a serem instalados em determinada bacia hidrográfica. No contexto presente, os quantis descritivos $Q_{90}$ e $Q_{95}$, além da estimativa inferencial $Q_{7,10}$ são comumente utilizadas para esse fim. As vazões de referência utilizadas, segundo Silva e Monteiro (2004), são as vazões mínimas, de forma a caracterizar uma condição de alta garantia de água no manancial. A partir dessa condição, são realizados os cálculos de alocação da água, de modo que, quando essas vazões mínimas ocorram, os usuários ou os usos prioritários mantenham, de certa forma, suas retiradas de água.

Dessa forma, a ANA (2011) afirma que quando o poder público analisa uma solicitação de outorga de um dado usuário, considerando uma captação a fio d'água em cursos d'água superficiais, ele deve considerar a vazão solicitada para o 
empreendimento frente ao percentual definido como outorgável em relação à vazão de referência adotada.

Nesse viés, o município de Rio Branco, no Estado do Acre, formalizou instrumento de outorga do direito de uso dos recursos hídricos somente em 2014, por meio da Resolução no 84, de 27 de janeiro de 2014. A finalidade principal apresentada foi para o abastecimento público, por meio da captação nas estações 1 e 2 no Rio Acre. Os efeitos legais de tal instrumento têm validade até a data de 15 de maio de 2042 .

Os estudos realizados a fim de serem emitidas as concessões de uso dos corpos hídricos muitas vezes desconsideram os aspectos de cada região, tomando como base os dispositivos de estados vizinhos ou parâmetros federais.

$\mathrm{Na}$ cidade de Rio Branco, para estudo da disponibilidade hídrica outorgável, foi utilizado o cálculo estabelecido pela Agência Nacional de Águas para o caso dos rios federais, ou seja, 70\% da Q95., conforme consta no Plano Estadual de Recursos Hídricos (SEMA, 2012), o qual foi elaborado antes da publicação da concessão da outorga pela ANA. Em termos nacionais, com relação à definição das outorgas e suas vazões de referência, a prática adotada é bastante diversa, como pode ser observado no Quadro 3.

QUADRO 3: Vazões de referência em alguns estados brasileiros

\begin{tabular}{|c|c|c|}
\hline $\begin{array}{l}\text { Vazão de } \\
\text { Refarôncia }\end{array}$ & \multicolumn{2}{|c|}{ Estados } \\
\hline$Q_{90}$ & $\begin{array}{c}\text { Bahia } \\
\text { Sergipe } \\
\text { Tocantins } \\
\text { Alagoas } \\
\text { Ceará } \\
\text { Espírito Santo }\end{array}$ & $\begin{array}{c}\text { Maranhão } \\
\text { Paraíba } \\
\text { Pernambuco } \\
\text { Piauí } \\
\text { Rio Grande do Norte }\end{array}$ \\
\hline$Q_{95}$ & \multicolumn{2}{|c|}{$\begin{array}{c}\text { Goiás } \\
\text { Paraná } \\
\text { Piauí } \\
\text { Mato Grosso }\end{array}$} \\
\hline$Q_{7,10}$ & \multicolumn{2}{|c|}{$\begin{array}{l}\text { Minas Gerais } \\
\text { São Paulo } \\
\text { Rio de Janeiro }\end{array}$} \\
\hline
\end{tabular}

Fonte: KOTZIAN (2010).e POMPEU et al., (2014)

\section{Evolução do sistema de abastecimento de água da cidade de Rio Branco/AC - Breve histórico}

A regulação que trata da implementação e prestação dos serviços de saneamento básico, no qual o abastecimento de água é um componente integrante, no estado do Acre, apresentou-se de maneira tardia (Quadro 4). O objetivo é visar ações de fiscalização e melhorias no setor, a fim de ofertar a população a prestação de serviços de qualidade e atingir o maior número de domicílios abastecidos com água. 
QUADRO 4: Regulação acerca da prestação de serviços de saneamento básico no estado do Acre

\begin{tabular}{|c|c|c|}
\hline Data & Legislação & Disposições Gerais \\
\hline 15 jan. 2003 & $\begin{array}{l}\text { Lei Estadual } n^{0} \\
1480\end{array}$ & $\begin{array}{l}\text { Cria a Agência Reguladora dos Serviços } \\
\text { Públicos do Estado do Acre }\end{array}$ \\
\hline 14 jan. 2014 & $\begin{array}{c}\text { Lei } \\
\text { complementar } \\
\mathrm{n}^{0} 278\end{array}$ & $\begin{array}{l}\text { Criação da Agência Reguladora dos Serviços } \\
\text { Públicos do Estado do Acre - AGEAC e } \\
\text { altera a lei no } 1.480 / 2003\end{array}$ \\
\hline 3 jun. 2015 & Decreto n 2633 & $\begin{array}{l}\text { Dispõe sobre a organização e o } \\
\text { funcionamento da Agência Reguladora dos } \\
\text { Serviços Públicos do Estado do Acre - } \\
\text { AGEAC }\end{array}$ \\
\hline 30 jun. 2015 & $\begin{array}{l}\text { Resolução no } \\
\text { 34/AGEAC }\end{array}$ & $\begin{array}{l}\text { Dispõe sobre a regulação da prestação dos } \\
\text { serviços de saneamento básico do Estado do } \\
\text { Acre e dá outras providências. }\end{array}$ \\
\hline 20 nov. 2017 & $\begin{array}{l}\text { Resolução no } \\
\text { 047/AGEAC }\end{array}$ & $\begin{array}{l}\text { Concede reajuste Tarifário para } \\
\text { Saneamento Básico do Estado do Acre. }\end{array}$ \\
\hline 17 set. 2019 & $\begin{array}{l}\text { Resolução no } \\
\text { 62/AGEAC }\end{array}$ & $\begin{array}{l}\text { Institui os procedimentos gerais, nas ações } \\
\text { de fiscalização da prestação dos serviços de } \\
\text { abastecimento de água potável e } \\
\text { esgotamento sanitário. }\end{array}$ \\
\hline 10 dez. 2019 & $\begin{array}{l}\text { Resolução no } \\
\text { 66/AGEAC }\end{array}$ & $\begin{array}{l}\text { Estabelece as condições de prestações de } \\
\text { serviços públicos de abastecimento de água } \\
\text { potável para consumo humano e } \\
\text { esgotamento sanitário no âmbito dos } \\
\text { municípios do Estado do Acre. }\end{array}$ \\
\hline 10 dez. 2020 & $\begin{array}{l}\text { Resolução no } \\
\text { 77/AGEAC }\end{array}$ & $\begin{array}{l}\text { Dispõe sobre as penalidades aplicáveis aos } \\
\text { prestadores de serviços públicos de } \\
\text { abastecimento de água e de esgotamento } \\
\text { sanitário. }\end{array}$ \\
\hline
\end{tabular}

Fonte: Autores (2021).

Com relação a implantação do sistema de abastecimento de água na cidade de Rio Branco, capital do Estado do Acre, Costa Filho (2016) relata que nenhuma das 27 capitais dos estados brasileiros passou por tantas mudanças institucionais na prestação dos serviços de saneamento. Tal medida compromete um alinhamento e seguimento de ações, vindo a refletir no avanço lento em garantir melhor atendimento à população.

Costa Filho (2016) relata que desde 1957 esse serviço é prestado na capital do Acre, sendo o primeiro sistema de abastecimento de água de Rio Branco sob a responsabilidade do Departamento de Obras e Viação (DOV). A estrutura compunha a administração direta do Território do Acre, que fez a instalação dos primeiros 200 metros de rede, instalados na área central da cidade. A estrutura de captação de água se dava por meio de estação elevatória em balsa flutuante no Rio Acre direto para um reservatório elevado com capacidade de $500 \mathrm{~m}^{3}$ que, por gravidade, distribuía a água bruta para a população. 
Com a elevação do Acre à categoria de Estado em 1962, o sistema passou à responsabilidade do Departamento de Água e Saneamento, na estrutura do Departamento de Obras e Viação do Estado (DOV), que posteriormente se transformaria em Secretaria de Obras. A cidade de Rio Branco cresceu em ritmo acelerado desde então, trazendo necessidade de ampliação no sistema de abastecimento e atendimento as demandas sanitárias (COSTA FILHO, 2016).

Em 1969, o Serviço Autônomo de Água e Esgoto do Acre (SAAE), uma autarquia estadual, substituiu a antiga estrutura de administração direta estadual. Em 1971, foi criada a Companhia de Saneamento do Estado do Acre S/A - SANACRE, que no ano de 1997 se apresentava em situação falimentar e não atendia mais às necessidades dos serviços na cidade, principalmente, o abastecimento de água. A crise foi tamanha que, os governos estadual e municipal decretaram estado de calamidade pública no setor. A companhia foi substituída pelo Serviço de Água e Esgoto de Rio Branco (SAERB), uma autarquia municipal (COSTA FILHO, 2016).

Já em 2012, foi estabelecida uma gestão compartilhada na prestação dos serviços, modalidade possibilitada pela edição das Leis 11.107/2005 (BRASIL, 2005) e 11.445/2007 (BRASIL, 2007). A prestação dos serviços foi delegada ao Governo Estadual, através do Departamento de Pavimentação e Saneamento do Estado do Acre (DEPASA), o qual foi renomeado futuramente para Departamento Estadual de Água e Saneamento (DEPASA) (COSTA FILHO, 2016).

Mais uma transição acordada em 2021, com a devolução e reversão da administração para a prefeitura de Rio Branco com a gestão do sistema de abastecimento de água e esgoto pelo Serviço de Água e Esgoto de Rio Branco (SAERB). A reversão se dará em 3 etapas, com vistas a se encerrar em outubro de 2021. O termo de encerramento do convênio de cooperação referente à gestão associada entre Prefeitura e Estado para a prestação dos serviços públicos de abastecimento de água e de esgotamento sanitário, que vinha ocorrendo desde 2012 no município, foi assinado pelo Governo do Estado e Prefeitura da capital, e publicado no diário oficial do estado no 13.060 em 09 de junho de 2021.

Atualmente, a captação de água é realizada no Rio Acre por meio de duas torres de tomada de água, denominadas ETA I e ETA II. A água bruta é então aduzida para as Estações de Tratamento (ETA), onde passa pelos processos de tratamento, tornando a água apta para consumo atendendo aos padrões de potabilidade. Assim ela é encaminhada aos centros de reserva para posterior encaminhamento ao consumidor final por meio das redes de distribuição e ligações domiciliares (LIMA, 2016).

De acordo com o Plano Diretor do Sistema de Abastecimento de Água (PMRB), do ano de 2000, o sistema de abastecimento de água de Rio Branco era composto pelas estruturas do $1^{\circ}$ e $2^{\circ}$ distrito, ETA Sobral e Judia, respectivamente. O Sistema Sobral, também denominado $1^{\circ}$ Distrito, está situado à margem esquerda do rio Acre, e utiliza como manancial o próprio Rio Acre. Este sistema era responsável por $92 \%$ da produção total de água consumida na cidade.

Já o Sistema Judia, também denominado $2^{\circ}$ Distrito, estava situado à margem direita do Rio Acre, abrangia a parte remanescente da cidade, e utilizava como manancial o igarapé Judia, contribuindo com apenas cerca de $8 \%$ da produção total do Sistema de Abastecimento de Água de Rio Branco. Esse sistema foi desativado em virtude do comprometimento do Igarapé Judia devido a degradação da bacia de drenagem por ação da crescente ocupação e lançamento de esgotos in natura em suas ENCICLOPÉDIA BIOSFERA, Centro Científico Conhecer - Jandaia-GO, v.18 n.37; p. 183 
águas. Além disso, o despejo de efluentes de lavagem de ônibus contendo detergente, graxas, óleos, oriundos de uma empresa de ônibus instalada as margens do igarapé, também poderia comprometer a qualidade da água (PMRB, 2000).

Em 2006 foi realizada a construção de uma nova Estação de Tratamento de Água, chamada ETA II, que atualmente é responsável pela maior parte da produção de água para abastecimento da cidade (LIMA, 2016).

\section{CONSIDERAÇÕES FINAIS}

O objetivo do presente estudo sucedeu em uma verificação nas visões e abordagens internacional e nacional quanto as diretrizes a respeito do direito ao acesso a água pelo ser humano, bem como a concessão do direito de uso como forma de proteção desse bem. Quanto à perspectiva local, cidade de Rio Branco, buscou-se discorrer um breve histórico do seu sistema de abastecimento de água.

A água, como parte do meio ambiente, fora mencionada em algumas ocasiões, embora seu reconhecimento como direito fundamental tenha sido tardio, já que nenhum texto internacional mencionava expressamente esse direito como fundamental, até a resolução da Assembleia Geral da ONU A/RES/64/292, em julho de 2010.

Observa-se, portanto, uma transformação no tratamento jurídico internacional da água potável nos últimos anos, onde a água era vista exclusivamente como objeto mercantil, passando por uma mudança expressiva de protegê-la e promovê-la como um direito humano fundamental, a fim de que as presentes e futuras gerações, possam ter assegurado seu acesso a fim de que seja efetivado o princípio da dignidade humana e do meio ambiente ecologicamente equilibrado.

Garantir água em quantidade e qualidade adequadas para todos os seres humanos e atividades econômicas em um mundo cada vez mais habitado, quente e seco é um dos grandes desafios da humanidade no século 21. As crises hídricas em diferentes regiões do planeta reforçam a urgência na construção de uma nova forma de viver e se relacionar com a água.

No Brasil, a proteção jurídica da água potável evoluiu na comunidade, pois se acentua a preocupação de se adotar um regime jurídico que vise o acesso e à gestão humanista eficiente desse recurso vital, por meio da concessão da outorga de uso da água.

O panorama nacional é de que três em cada dez domicílios urbanos ainda não são abastecidos com água potável. Nas regiões com menor acesso a rios, nascentes e aquíferos, o atendimento é precário. Nas áreas e bairros mais pobres, o mesmo cenário. De acordo com o Sistema Nacional de Informações de Saneamento (SNIS), no ano de 2018, a cobertura do sistema de abastecimento de água, no Brasil, foi de $83,6 \%$ da população.

Com o novo marco legal de saneamento, Lei no 14.026, aprovada em 2020, espera-se que ocorra aumento do índice de acesso ao saneamento básico no Brasil, especialmente no tocante à ampliação da cobertura de abastecimento de água potável, com vistas à sua universalização. Tal objetivo já foi alcançado nas capitais Curitiba (PR), Goiânia (GO) e Brasília (DF), conforme divulgado no Ranking ABES da Universalização do Saneamento (2021), os quais apresentaram índices de atendimento de $100 \%, 99,18 \%$ e $99,0 \%$, respectivamente.

No contexto da cidade Rio Branco-Acre, as diversas alternâncias que ocorreram na gestão e operacionalização do sistema de abastecimento de água da cidade ENCICLOPÉDIA BIOSFERA, Centro Científico Conhecer - Jandaia-GO, v.18 n.37; p. 184 
demonstraram que as mudanças envolveram questões complexas. Porém tais mudanças não melhoraram significativamente a prestação dos serviços no sentido de alcançar o acesso universal para toda a população, visto que, apenas $52,66 \%$ da população total da cidade é atendida com rede de abastecimento de água, segundo o Sistema Nacional de Informações sobre Saneamento (SNIS) referente ao ano de 2018.

No que tange a segurança hídrica na capital do Acre, o painel atual mostra-se distante daquele apresentado em 2012 no Plano Estadual de Recursos Hídricos. A verdade é que, a cada ano que passa, durante o período de escassez de chuvas, influenciado pela forte sazonalidade do regime hidrológico da região, a população de Rio Branco tem sofrido com a falta de água em suas residências, precisando enfrentar racionamento e rodízio no abastecimento.

Do ponto de vista ambiental, carece de um olhar mais atento quanto a concessão do volume outorgável para captação de água do Rio Acre, e que represente a realidade do corpo hídrico, que com o avançar dos anos, apresenta uma lâmina d'água cada vez menor no período de seca, sinal de evidente comprometimento de sua capacidade.

\section{REFERÊNCIAS}

ABES - Associação Brasileira de Engenharia Sanitária e Ambiental. Ranking ABES da Universalização do Saneamento. Edição 2021. Disponível em: <http://abesdn.org.br/?page_id=41939> Acesso em 9 jul. 2021.

ACRE. Decreto no 2.633, de 5 de junho de 2015. Dispõe sobre a organização e o funcionamento da Agência Reguladora dos Serviços Públicos do Estado do Acre AGEAC. Diário oficial do Estado do Acre. № 11.571, de 09 jun. 2015.

ACRE. Lei complementar no 278 de 14 de janeiro de 2014. Cria a Agência Reguladora dos Serviços Públicos do Estado do Acre - AGEAC. Diário Oficial do Estado do Acre. no 11.222, de 15 jan. 2003.

ANA - Agência Nacional de Águas e Saneamento. Outorga de direito de uso dos recursos hídricos. Conjuntura recursos hídricos Brasil. Brasília. 2019.

ANA - Agência Nacional de Águas e Saneamento. Outorga de direito de uso dos recursos hídricos. Caderno de capacitação em recursos hídricos. Brasília. 2011.

AGEAC - Agência Reguladora de serviços públicos do estado do Acre. Resolução no. 034 /AGEAC, de 30 de junho de 2015. Dispõe sobre a regulamentação da prestação dos serviços de saneamento básico do Estado do Acre e dá outras providências. Diário Oficial do Estado do Acre, AC. nำ11.594, de 10 jul. 2015.

AGEAC - Agência Reguladora de serviços públicos do estado do Acre. Resolução no 047/AGEAC, de 20 de novembro de 2017. Concede Reajuste Tarifário para o Saneamento Básico do Estado do Acre. Diário Oficial do Estado do Acre, AC. no 12.182, de 21 nov. 2017.

AGEAC - Agência Reguladora de serviços públicos do estado do Acre. Resolução no. 062/AGEAC, de 17 de setembro de 2019. Institui os procedimentos gerais, nas ações ENCICLOPÉDIA BIOSFERA, Centro Científico Conhecer - Jandaia-GO, v.18 n.37; p. 185 
de fiscalização da prestação dos serviços de serviços de abastecimento de água potável e esgotamento sanitário. Diário Oficial do Estado do Acre, AC. ํㅜ 12.672, de 05 nov. 2019.

AGEAC - Agência Reguladora de serviços públicos do estado do Acre . Resolução no. 066/AGEAC, de 10 de dezembro de 2019. Estabelece as condições gerais de prestação de serviços públicos de abastecimento de água potável para consumo humano e de esgotamento sanitário no âmbito dos municípios do Estado do Acre. Diário Oficial do Estado do Acre, AC. № 12.698, de 11 dez/ 2019.

AGEAC - Agência Reguladora de serviços públicos do estado do Acre. Resolução no. 077/AGEAC de 10 de dezembro de 2020. Dispõe sobre as penalidades aplicáveis aos prestadores de serviços públicos de abastecimento de água e de esgotamento sanitário. Diário Oficial do Estado do Acre, AC. ํㅜ 12.941, de 14 dez. 2020.

\section{BRANCO, O. E. A. Avaliação da disponibilidade hídrica: conceitos e aplicabilidade.} 2006.

<https://www.ufff.br/engsanitariaeambiental/files/2012/04/Disponibilidade-

H\%C3\%ADdrica.pdf>. Acesso em 14 dez. 2020

BRASIL. Constituição (1988). Constituição da República Federativa do Brasil. Brasília, DF: Senado Federal: Centro Gráfico, 1988.

BRASIL. Lei no 9.433, de 08 de janeiro de 1997. Institui a Política Nacional de Recursos Hídricos, cria o Sistema Nacional de Gerenciamento de Recursos Hídricos, regulamenta o inciso XIX do art. 21 da Constituição Federal, e altera o art. $1^{\circ}$ da Lei $\mathrm{n}^{\circ}$ 8.001, de 13 de março de 1990, que modificou a Lei no 7.990, de 28 de dezembro de 1989. Diário Oficial da União, Brasília, DF, 09 jan. 1997. Seção 1, p. 470.

BRASIL. Lei no 11.107, de 06 de abril de 2005. Dispõe sobre normas gerais de contratação de consórcios públicos e dá outras providências. Diário Oficial da União, Brasília, DF, 07 abr. 2005. Seção 1, p. 1

BRASIL. Lei no 11.445, de 05 de janeiro de 2007. Estabelece as diretrizes nacionais para o saneamento básico; cria o Comitê Interministerial de Saneamento Básico; altera as Leis nos 6.766, de 19 de dezembro de 1979, 8.666, de 21 de junho de 1993, e 8.987, de 13 de fevereiro de 1995; e revoga a Lei ํㅜ 6.528, de 11 de maio de 1978.Diário Oficial da União, Brasília, DF, 08 jan. 2007. Seção 1, p. 3.

CASTRO, L. S. Direito fundamental de acesso a água potável e a dignidade da pessoa humana. Âmbito Jurídico. Ambiente Jurídico, São Paulo, 2013. Disponível em: <https://ambitojuridico.com.br/edicoes/revista-117/direito-fundamental-de-acesso-aagua-potavel-e-a-dignidade-da-pessoa-humana/>. Acesso em 12 mar. 2021.

CONTI, I. L.; SCHROEDER, E. O. Convivência com o semiárido brasileiro. Autonomia e protagonismo social. Editora IABS. Brasília. 2013. 
COSTA FILHO, O. S. Alternância do poder ou poder da alternância? As agendas dos serviços de abastecimento de água e esgotamento sanitário em Rio Branco, Acre. Tese (Doutorado em Saneamento, Meio Ambiente e Recursos Hídricos). Escola de Engenharia. Universidade Federal de Minas Gerais, 2016.

DIAS, R. B. Tecnologias sociais e políticas públicas: lições de experiências internacionais ligadas à água. Inclusão Social, v. 4, n. 2, p. 56-66, 2011. Disponível em: <http://revista.ibict.br/inclusao/article/view/1656>

EICHENBERGER, A. M. R.; SOUZA, T. S.; NASCIMENTO, P. S. Tendência e correlação da vazão e da precipitação pluviométrica no município de Valença-BA. GeoFronter, v. 6, p. 01-20, 2020. Disponível em: <https://periodicosonline.uems.br/index.php/GEOF/article/view/5449>

FIOREZE, A. P.; OLIVEIRA, L. F. C. Usos dos recursos hídricos da Bacia Hidrográfica do Ribeirão Santa Bárbara, Goiás, Brasil. Pesquisa Agropecuária Tropical, v.40, n.1, p.28-35. 2010. Disponível em: <https://www.revistas.ufg.br/pat/article/view/3869> doi: 10.5216/pat.v40i1.3869

KOTZIAN, H. Plano de gerenciamento da bacia hidrográfica do rio dos Sinos. Universidade Do Vale do Rio dos Sinos. Consórcio Pró-Sinos. Comitesinos. São Leopoldo, 2010.

LIMA, A. M. P. Padrão de potabilidade da água distribuída pelas estações de tratamento do município de Rio Branco-AC. Dissertação (Mestrado em Ciência, Inovação e Tecnologia para a Amazônia). Universidade Federal do Acre. 2016.

LUCENA, R. G. R.; RAZZOLINI, M. T. P.; MENEZES, L. M. B.; MARQUES, R. A. A.; NARVAI, P. C. Significados da água na visão de liderança de saúde. Saúde e Sociedade, v. 22, n. 4, p. 1193-1204, 2013. Disponível em: <https://doi.org/10.1590/S0104-12902013000400020> doi: 10.1590/S010412902013000400020

MACHADO, P.A.L.; Recursos Hídricos: direito brasileiro e internacional. Malheiros Editores, 2002.

MAIA, I. L. B. O acesso à água potável como direito humano fundamental no direito brasileiro. Revista do CEPEJ, v. 20, p. 301-338, 2017. Disponível em: < https://periodicos.ufba.br/index.php/CEPEJ/article/view/27165>

MAZARO, G.; Água é um direito humano? Politizei. 2021. Disponível em: <https://www.politize.com.br/agua-direito-humano/>. Acesso em 09 mar. 2021

MORAES, D. S. L.; JORDÃO, B. Q. Degradação de recursos hídricos e seus efeitos sobre a saúde humana. Revista de Saúde Pública, São Paulo, v. 36, n. 3, p. 370-374, 2002. Disponível em: <https://doi.org/10.1590/S0034-89102002000300018> doi: 10.1590/S0034-89102002000300018 
NASCIMENTO, N. O.; HELLER, L. Ciência, tecnologia e inovação na interface entre as áreas de recursos hídricos e saneamento. Engenharia Sanitária e Ambiental, Rio de Janeiro, v. 10, n. 1, p. 36-48, 2005. Disponível em: <https://doi.org/10.1590/S141341522005000100005> doi: 10.1590/S1413-41522005000100005

OLIVEIRA, L. F.C.; FIOREZE, A, P. Estimativa de vazões mínimas mediante dados pluviométricos na bacia hidrográfica do Ribeirão Santa Bárbara, Goiás. Revista Brasileira de Engenharia Agrícola e Ambiental, v.15, n.1, p.9 - 15. 2011. Disponível em: <https://doi.org/10.1590/S1415-43662011000100002> doi: 10.1590/S141543662011000100002

ONU - Organização das Nações Unidas. Assembléia Geral da Onu (AG). Resolução A/RES/64/292, 28 de julho de 2010. Disponível em: <https://www.un.org/ga/search/view_doc.asp?symbol=A/RES/64/292>. Acesso em 02 fev. 2021.

ONU - Organização das Nações Unidas. Relatório Mundial das Nações Unidas sobre Desenvolvimento dos Recursos Hídricos - 2019. Disponível em: <unesdoc.unesco.org/ark:/48223/pf-0000367303_por>. Acesso em 26 nov 2020.

PMRB - Prefeitura Municipal de Rio branco. Plano Diretor do Sistema de Abastecimento de Água. Rio Branco. SAERB Serviço de Água e Esgoto de Rio Branco, 2000.

PNUD - Programa das Nações Unidas para o Desenvolvimento. A água para lá da escassez: poder, pobreza e a crise mundial da água. Nova lorque, 2006. Disponível em: <http://hdr.undp.org/en/media/01_HDR06\%20frontmatter_PT_revCA.pdf>. Acesso em 12 mar. 2021

POMPEU, R. D. M.; ALMAGRO, A.; ALMEIDA, L. F. R.; SOBRINHO, T. A. A outorga de direito de uso de recursos hídricos. XXII Simpósio de Recursos Hídricos do Nordeste. Associação Brasileira de Recursos Hídricos. Anais. Natal, 2014. Disponível em: $<$ https://anais.abrhidro.org.br/job.php?Job=7613>

PONTES, C. A. A.; SCHRAMM, F. R. I. Bioética da proteção e papel do Estado: problemas morais no acesso desigual à água potável. Cadernos de Saúde Pública, Rio de Janeiro, v. 20, n. 5, p. 1319-1327, 2004. Disponível em: <https://doi.org/10.1590/S0102-311X2004000500026> doi: 10.1590/S0102311 X2004000500026

RAZZOLINI, M. T. P.; GÜNTHER, W. M. R. Impactos na Saúde das Deficiências de Acesso a Água. Saúde e Sociedade, v. 17, n. 1, p. 21-32, 2008. Disponível em: <https://doi.org/10.1590/S0104-12902008000100003> doi: 10.1590/S010412902008000100003 
REYMÃO, A. E.; SABER, B. A. Acesso à água tratada e insuficiência de renda duas dimensões do problema da pobreza no Nordeste Brasileiro sob a óptica dos objetivos de desenvolvimento do milênio. Revibec: Revista Iberoamericana de Economía Ecológica, Barcelona, v. 12, p. 1-15, out. 2009. Disponível em: <https://raco.cat/index.php/Revibec/article/view/164730>

RIBEIRO, C. B. M; MARQUES, F. A.; SILVA, D. D. Estimativa de regionalização de vazões mínimas de referência para a bacia do Rio Doce. Engenharia na Agricultura. Viçosa, MG, v. 13, n. 2, p. 103-107, 2005. Disponível em: <https://www.researchgate.net/publication/315815437_Estimativa_e_regionalizacao_de _vazoes_minimas_de_referencia_para_a_bacia_do_rio_Doce>

SARRETA, C.R.L.; Sociologia do Direito à água percepções sociais, ambientais e culturais dos atores diante do direito universal à água e do processo de privatização. Tese (Doutorado em Ciências Sociais). Universidade do Vale do Rio dos Sinos, São Leopoldo, 2013.

SCHRAMM, F. R.; KOTTOW, M. Princípios bioéticos en salud pública: limitaciones y propuestas. Cadernos de Saúde Pública, Rio de Janeiro, v. 17, n. 4, p. 949-956, 2001. Disponível em: <https://doi.org/10.1590/S0102-311X2001000400029> doi: 10.1590/S0102-311X2001000400029

SELBORNE, E. L. A ética do uso da água doce: um levantamento. Brasília, DF: Unesco, 2002.

SILVA, A. M.; OLIVEIRA, P. M.; MELLO, C. R.; PIERANGELI, C. Vazões mínimas e de referência para outorga na região do Alto Rio Grande, Minas Gerais. Revista Brasileira de Engenharia Agrícola e Ambiental, v.10, n.2, p.374-380, 2006. Disponível em: <https://doi.org/10.1590/S1415-43662006000200019> doi: 10.1590/S141543662006000200019

SILVA, L. M. C.; MONTEIRO, R. A. Outorga de direito de uso de recursos hídricos: uma das possíveis abordagens. In: Machado, C. J. S. (Org.). Gestão de águas doces. Rio de Janeiro: Interciência. Cap. 5, p.135-178. 2004. Disponível em: <https://www.docsity.com/pt/capitulo-outorga-livro-da-uerj-versao-final/4797050/>

SNIS - Sistema Nacional de Informações sobre saneamento. Diagnóstico dos Serviços de Água e Esgotos - 2018. Diagnósticos dos serviços de água e esgoto. $2019 . \quad$ Disponível em: <http://www.snis.gov.br/downloads/diagnosticos/ae/2018/Diagnostico_AE2018.pdf>. Acesso em 12 de fev. 2021.

TRINDADE, A. L. C.; ALMEIDA, K. C. B.; BARBOSA, P. E.; OLIVEIRA, S. M. A. C. Tendências temporais e espaciais da qualidade das águas superficiais da sub-bacia do Rio das Velhas, estado de Minas Gerais. Engenharia Sanitária Ambiental, v. 22, n. 1, 2017. Disponível em: <https://doi.org/10.1590/S1413-41522016131457> doi: 10.1590/S1413-41522016131457 
VON SPERLING, M. Estudos e modelagem da qualidade da água de rios. 7. Ed. Belo Horizonte, MG: Ed. Universidade Federal de Minas Gerais. 588p. 2007.

WHO - World Health Organization and UNICEF. Progress on Sanitation and Drinking-Water: 2014 update. Disponível em: <http://apps.who.int/iris/bitstream/handle/10665/112727/9789241507240_eng.pdf?sequ ence $=1>$. Acesso em 31 jan. 2021. 